\title{
ECS effects: An attempt to stimulate recovery of the PRE*
}

\section{A. GRANT YOUNG and G. DWAYNE FUSELIER Louisiana State University, Baton Rouge, La. 70803}

Eighty naive male albino rats were trained to leverpress for sucrose on either continuous reinforcement (CRF) or partial reinforcement (PR). Following training, $S$ experienced treatment consisting of either footshock plus ECS or footshock only. Four hours after original treatment, half of the Ss in each group received a "reminder" shock. Results of an extinction test $24 \mathrm{~h}$ after original treatment showed that: (1) ECS produced apparent amnesia for footshock, (2) ECS eliminated the partial reinforcement effect (PRE), (3) "reminder" shock produced at least partial recovery from ECS-induced amnesia, and (4) "reminder" shock did not reinstate the PRE. Results were interpreted as not supportive of a memory consolidation hypothesis.

When electroconvulsive shock (ECS) is administered shortly after a learning experience, the result appears to be retrograde amnesia (RA) for that learning experience (Lewis, 1969; Spevack \& Suboski, 1969). The phenomenon has been explained by a memory consolidation hypothesis which suggests that, following sensory input, a physiological consolidation process (i.e., reverberatory activity) operating over time permanently fixes the memory trace. It is assumed that during the consolidation process the memory trace is relatively unstable and susceptible to disruption (McGaugh, 1966). If head trauma, such as the massive electrical interference produced by ECS, is experienced by the organism during the short-term process, the consolidation process is disrupted such that permanent fixation of the memory trace does not occur.

In order to separate the amnesic effect of ECS from any possible aversive effects, a typical procedure is to administer aversive stimulation, such as footshock, upon the emission of a learned response. The aversive stimulation results in a suppressed rate of responding; however, if ECS shortly follows the aversive stimulation, the apparent result is RA for this one-trial learning experience, since response suppression does not occur.

Two lines of recently produced evidence seem to question the efficacy of a memory consolidation hypothesis to account for the effects of ECS. One line of evidence is that produced by a series of studies (Young \& Day, 1970; Young \& Day, 1971; Young \& Galluscio, 1970; Young \& Galluscio, 1971) which indicate that, when Ss are trained on a partial reinforcement schedule $(\mathrm{PR})$ and then experience aversive stimulation

*This research was supported in part by a grant from the University Council on Research, Louisiana State University, to the first author. immediately followed by ECS, they are no different in extinction tests from like-treated Ss that have been trained on a continuous reinforcement schedule (CRF). For example, Young \& Day (1971) trained rats to leverpress for sucrose. One group was trained on a VR 2 schedule and the other was trained on CRF. Upon completion of acquisition, treatment, which consisted of footshock followed immediately by ECS, was produced by a leverpress. In an extinction session $24 \mathrm{~h}$ later, there was no significant difference in the number of responses made by the two groups.

The administration of ECS, then, appears to erase the partial reinforcement effect (PRE)-the greatly increased resistance to extinction shown by PR-trained Ss. It is not at all clear that a memory consolidation hypothesis would predict this result. If ECS interrupts a consolidation process such that the memory trace for footshock does not become permanently fixed, presumably the acquisition reinforcement schedule would be an irrelevant variable.

Another line of evidence which does not support a memory consolidation hypothesis comes from studies which show recovery from ECS-induced RA following a "reminder shock" (Lewis, 1969). For example, Galluscio (1971) trained rats to leverpress for sucrose. Following acquisition, Ss experienced either footshock only or footshock followed immediately by ECS. Four hours after initial treatment, half of the Ss in each group experienced a "reminder" footshock, in a different apparatus and under different stimulus conditions. Twenty-four hours after initial treatment, all Ss were subjected to an extinction test. Results showed that ECS produced apparent RA for the footshock in those Ss that did not experience the reminder shock. The effect of the reminder shock was apparent recovery from ECS-induced RA and a reinstatement of response suppression. If, as consolidation theory presumes, ECS disrupts the fixation of the memory trace for footshock, then it should not be possible to ?einstate that memory.

These studies showing recovery from ECS-induced RA have used a CRF training schedule, and the purpose of this experiment was to replicate the findings of Galluscio (1971) in order to determine (1) whether recovery from RA can be consistently demonstrated, and (2) if such recovery from RA does occur (i.e., response suppression is reinstated), whether the PRE will likewise be reinstated.

\section{METHOD \\ Subjects}

The Ss were 80 naive male albino rats, $175-200 \mathrm{~g}$ in weight at the start of the experiment. 
Apparatus

The apparatus consisted of two identical Scientific Prototype operant chambers, each enclosed in a sound-insulated ventilated cubicle. Each operant chamber had a grid floor, and fitted on the end wall was a retractable lever and a liquid dipper which dispensed $.01 \mathrm{ml}$ of a $40 \%$ sucrose solution, used as reinforcement.

A separate box $\left(4 \frac{1}{2} \times 6 \frac{1}{2} \times 5 \frac{1}{2}\right.$ in. wide), made of $1 / 4$-in. Plexiglas, was used to administer a reminder shock. This box had a grid floor of $1 / 4$-in. bronze rods, set apart $5 / 8$ in. on centers.

All E-controlled events were operated by an electronic programming device.

\section{Procedure}

The Ss were selected randomly from the LSU colony and placed in individual cages on ad lib food and water for 4 days, after which they were placed on a food-deprivation schedule of $10 \mathrm{~g}$ Purina Chow every $24 \mathrm{~h}$. Water was available in the cages at all times, and Ss were fed approximately $10 \mathrm{~min}$ after each experimental session.

From Days 5-9, Ss were handled in pairs for $5 \mathrm{~min}$ each day, and from Days $10-13$, Ss were given magazine training on a VI $30-\mathrm{sec}$ schedule. Experimental periods consisted of 20 presentations of the dipper and continued for 4 days.

On Day 14 all Ss were trained to leverpress and were allowed to make 50 reinforced responses. On the following day, all Ss were allowed to make 100 reinforced responses.

On Day 16 the Ss were divided randomly into two groups (FR and $\mathrm{CR}$ ) and began acquisition training. For the FR group, acquisition was under a FR 2 schedule for the first 5 days and under a FR 3 schedule for the next 5 days. For the CR group, acquisition was under a CRF schedule throughout. All Ss were given 100 leverpresses daily for 10 days. A discrete trial procedure was used and the lever, which required $4 \mathrm{sec}$ to retract and extend fully, was inoperative during retraction.

On the day following completion of acquisition, each group was subdivided randomly, resulting in the following eight groups $(\mathrm{N}=10)$ :

\section{Groups $C R(E C S)$ and $F R(E C S)$}

On treatment day, Ss in these two groups were fitted with a harness. Fine wire from an ECS source, which entered the operant chamber from the top, was connected to the harness, and from the harness to microalligator clip electrodes attached to the S's ears. The harness permitted complete freedom of movement to all parts of the operant chamber. The first leverpress produced a 9-mA footshock of 2-sec duration, delivered through the grid floor, and the lever retracted. The offset of footshock initiated the onset of a $50-\mathrm{mA} 500-\mathrm{msec}$ ECS, delivered through the earclip electrodes.

\section{Groups $C R(S O)$ and $F R(S O)$}

For Ss in these two groups, treatment was identical to that of the CR(ECS) and FR(ECS) groups, except that footshock was not followed by ECS.

\section{Groups $C R(E C S) R$ and $F R(E C S) R$}

The $S s$ in these two groups received treatment identical to that of the CR(ECS) and FR(ECS) groups. In addition, these Ss received a reminder footshock, which was identical to the first footshock and was administered $4 \mathrm{~h}$ following original treatment. The stimulus conditions for the reminder shock were made as different as possible from the shock given in the operant chamber by using the special shock box in a separate darkened room.

\section{Groups $C R(S O) R$ and $F R(S O) R$}

The $S s$ in these two groups received original treatment identical to that of the CR(SO) and FR(SO) groups. In addition, $4 \mathrm{~h}$ later they received the reminder shock in an identical fashion as that to Groups CR(ECS)R and FR(ECS)R.
All Ss were given a 10 -min extinction session $24 \mathrm{~h}$ following original treatment. During extinction, stimulus conditions were the same as during acquisition, with the exception that the dipper was inoperative.

\section{RESULTS AND DISCUSSION}

The number of responses made by each $S$ in extinction was recorded at the r.nd of the first minute; results showed that more responses were made by Group CR(ECS), followed in order by Groups FR(ECS), FR(ECS)R, CR(ECS)R, FR(SO), CR(SO), FR(SO)R, and $\mathrm{CR}(\mathrm{SO}) \mathrm{R}$. These data were subjected to an analysis of variance which showed that the main effects of reminder shock and treatment both were significant beyond the .01 level. The Reminder Shock by Treatment interaction was significant beyond the .05 level, and these data were, therefore, subjected to an analysis of variance for simple effects. Results showed that the effect of reminder shock was significant beyond the .01 level for the ECS groups but was not significant at the .05 level for the SO groups. Results also showed that the effect of treatment was significant beyond the .01 level for both reminder shock and no reminder shock groups.

Group comparisons ( $t$ ) for the reminder shock main effect showed that differences between Groups CR(ECS) vs CR(ECS)R and FR(ECS) vs FR(ECS)R were significant beyond the .01 level. Group comparisons $(t)$ for the treatment main effect showed that Groups $\mathrm{CR}(\mathrm{ECS})$ vs $\mathrm{CR}(\mathrm{SO})$ and $\mathrm{FR}(\mathrm{ECS})$ vs $\mathrm{FR}(\mathrm{SO})$ were significant beyond the .01 level and that Groups CR(ECS)R vs CR(SO)R and FR(ECS)R vs FR(SO)R were significant beyond the .05 level.

The total number of responses made by each $S$ for the 10-min extinction period were recorded; results showed that more responses were made by Group FR(ECS), followed in order by Groups CR(ECS), FR(ECS)R, CR(ECS)R, FR(SO), FR(SO)R, CR(SO), and CR(SO)R. These data were subjected to an analysis of variance which showed that all three main effects, reminder shock, treatment, and schedule, were significant beyond the .01 level. The Reminder Shock by Treatment interaction also was significant beyond the .01 level, and these data were, therefore, subjected to an analysis of variance for simple effects. Results showed that the effect of reminder shock was significant beyond the .01 level for the ECS groups but was not significant at the .05 level for the SO groups. In fact, the SO group means were almost identical. Results also showed that the effect of ECS was significant beyond the .01 level for reminder shock and no reminder shock groups.

Group comparisons ( $t$ ) for the reminder shock main effect showed that the comparisons FR(ECS) vs FR(ECS)R and CR(ECS) vs CR(ECS)R were significant beyond the .01 level. Group comparisons $(t)$ for the treatment (ECS) main effect showed the following comparisons significant beyond the .01 level: FR(ECS) vs FR(SO), $\mathrm{CR}(\mathrm{ECS})$ vs $\mathrm{CR}(\mathrm{SO}), \mathrm{CR}(\mathrm{ECS}) \mathrm{R}$ vs $\mathrm{CR}(\mathrm{SO}) \mathrm{R}$, and the comparison FR(ECS)R vs FR(SO)R 
was significant beyond the .05 level. Group comparisons (t) for the schedule main effect showed that the comparisons $\mathrm{FR}(\mathrm{SO}) \mathrm{R}$ vs $\mathrm{CR}(\mathrm{SO}) \mathrm{R}$ and $\mathrm{FR}(\mathrm{SO})$ vs $\mathrm{CR}(\mathrm{SO})$ were significant beyond the .01 level. The comparisons FR(ECS)R vs CR(ECS)R and FR(ECS) vs CR(ECS) did not approach statistical significance. The mean number of leverpresses in extinction for all groups is shown in Table 1.

Acquisition response rates for the last 2 days of acquisition were recorded; comparisons showed no significant differences within FR-trained groups or within CR-trained groups, but acquisition response rates were significantly slower $(p<.05$, Mann-Whitney $U)$ for FR-trained Ss than for CR-trained Ss due to the discrete trial procedure.

The finding that the ECS groups made significantly more responses in extinction than did the SO groups is consistent with earlier findings which suggest that ECS produces RA for footshock and is easily explained in terms of consolidation theory. However, the finding that the reminder shock was an effective suppressor only in the ECS groups, and in those groups effected at least partial recovery from RA, is not consistent with consolidation theory. These findings replicate those of Galluscio (1971) and suggest that a memory consolidation hypothesis does not adequately explain ECS-induced amnesia.

Lewis (1969) suggested that ECS, rather than interrupting the fixation of a memory trace, operates on processes which occur subsequent to memory fixation The supposition is, then, that memory fixation is almost instantaneous with sensory input and that ECS inhibits the retrieval mechanism or process necessary for the expression of that memory. The findings of this study could be interpreted to support such a position.

The finding that ECS eliminates the PRE is also consistent with earlier findings and was expected.

A critical finding of this study is that, although reminder shock apparently produced a partial recovery from RA for the footshock, it did not reinstate the PRE. Although the PRE was evident for the SO groups and the SO plus reminder shock groups, it was only the
Table 1

Mean Number of Leverpresses in Extinction

\begin{tabular}{lcclccc}
\hline & First & & \multicolumn{3}{c}{ First } \\
Group & Minute & Total & & Group & Minute & Total \\
\hline CR(ECS) & 8.5 & 47.6 & CR(ECS)R & 3.1 & 30.9 \\
CR(SO) & 1.0 & 11.0 & CR(SO)R & 0.1 & 10.8 \\
FR(ECS) & 6.8 & 52.5 & FR(ECS)R & 3.7 & 36.9 \\
FR(SO) & 1.7 & 27.0 & FR(SO)R & 0.2 & 25.9 \\
\hline
\end{tabular}

groups which experienced ECS that failed to show the PRE, and this effect appears to be permanent. Why ECS should eliminate the PRE is not at all clear. Young \& Day (1971) suggest that the effect of ECS is not the disruption of a memory trace resulting in RA but, perhaps through a type of disinhibition, the effect is an inflated rate of responding or a perseveration of responding in extinction. Although this interpretation is tenable, it is not clear whether the PRE is lost through a reduction in responding in extinction for PR-trained Ss or through an increase in responding in extinction for CRF-trained Ss. Either effect would result in a smaller difference between the two groups, with a resulting loss of the PRE.

\section{REFERENCES}

Galluscio, E. H. Retrograde amnesia induced by electroconvulsive shock and carbon dioxide anesthesia: An attempt to stimulate recovery. Journal of Comparative \& Physiological Psychology, 1971, 75, 136-140.

Lewis, D. J. Sources of experimental amnesia. Psychological Review, 1969, 76, 461-472.

McGaugh, J. L. Time-dependent processes in memory storage. Science, 1966, 153, 1351-1358.

Spevack, A. A., \& Suboski, M. D. Retrograde effects of electroconvulsive shock on learned responses. Psychological Bulletin, 1969, 72, 66-76.

Young, A. G., \& Day, H. D. ECS effects following continuous and partial reinforcement training. Psychonomic Science, $1970,21,131-132$.

Young, A. G., \& Day, H. D. Effect of ECS on one-trial learning and on the partial reinforcement effect. Psychonomic Science, $1971,24,99-100$.

Young, A. G., \& Galluscio, E. H. Failure of ECS to produce retrograde amnesia following partial reinforcement training. Psychonomic Science, 1970, 18, 175-176.

Young, A. G., \& Galluscio, E. H. Recovery from ECS-produced amnesia. Psychonomic Science, 1971, 22, 149-151.

(Received for publication February 12, 1973.) 